\title{
Praxiologia Motriz: instrumentalizando a prática pedagógica para o ensino dos esportes coletivos
}

\author{
João Francisco Magno Ribas ${ }^{1}$ \\ ${ }^{1}$ Departamento de Desportos Coletivos da Universidade Federal de Santa Maria, Santa \\ Maria, RS, Brasil \\ ${ }^{2}$ GPELF-Grupo de Pesquisa em Lazer e Formação de Professores
}

\begin{abstract}
Resumo: A Praxiologia Motriz se constitui atualmente num relevante olhar relativo aos jogos e esportes que se dedica a compreender a essência de funcionamento dessas manifestações. Neste artigo construo, a partir dos universais dos jogos e esportes de Pierre Parlebas idealizador da Praxiologia Motriz, análises pertinentes à lógica interna de Jogos Esportivos Coletivos, tomando como exemplo o handebol, desvelando assim, características essenciais que pouco vêm sendo exploradas e consideradas no processo de compreensão e, consequentemente, do ensino. O estudo aponta para a necessidade de aprofundar ainda mais em reflexões que aproximem e situem o conhecimento praxiológico na instrumentalização de professores e alunos para que se construa um conhecimento melhor elaborado sobre os esportes, tendo em vista as abordagens críticas da Educação Física.
\end{abstract}

Palavras-chave: Praxiologia Motriz; Ensino; Educação; Esporte.

\section{Motor Praxeology: Instrument to the pedagogical practice for teaching of sports collectives}

\begin{abstract}
Currently, the Motor Praxeology is a meaningful glance at games and sports and it focuses on understanding the operational core of these manifestations. In this article, based on the universals of games and sports by Pierre Parlebas, I have made some analyses regarding the internal logic of Collective Sport Games using handball as an example, thus unveiling essential characteristics that have been little explored and considered in the comprehension process and, accordingly, in the teaching process. The study points out the need to deepen still more the reflections that approach and place the praxeological knowledge as to the training of teachers and students, so that we can build better and in depth sport knowledge, taking into account the Physical Education critical approaches.
\end{abstract}

Key Words: Motor Praxeology; Teaching; Education; Sport.

\section{Introdução}

As metodologias de ensino dos Jogos Esportivos Coletivos (JEC) vêm aproximando ainda mais os espaços pedagógicos e a dinâmica de ensino. Autores como Claude Bayer, na França, Graça e Oliveira, que coordenaram uma importante obra sobre o tema em Portugal, Hernández Moreno e Riera, na Espanha, têm sistematizado este conhecimento em forma de livros que evidenciam novas e importantes contribuições para o processo de EnsinoAprendizagem dos jogos esportivos coletivos. No Brasil, o professor Pablo Juan Greco da Universidade Federal de Minas Gerais, com forte influência desses autores e da produção alemã, principalmente do professor Klauss Roth, escreveu, junto com um grupo de colaboradores, a obra Iniciação Esportiva Universal em 1998 (GRECO, 1998). Todos os autores acima citados, direta ou indiretamente, foram ou são influenciados por um conhecimento comum: a Praxiologia Motriz.

A organização dessas novas sistematizações metodológicas só foi possível porque a Praxiologia Motriz vem colaborando com instrumentos de compreensão da dinâmica e lógica interna de funcionamento de jogos e esportes, trazendo à tona a necessidade de novas organizações das práticas pedagógicas que, em linhas gerais, devem contemplar a compreensão e ensino das interações (cooperação e oposição) que acontecem nesse grupo de modalidades. As novas sistematizações metodológicas propostas pelos autores contemporâneos que tematizam os JEC se sustentam por considerarem que este grupo de modalidade possui as seguintes características: todo o participante é portador de mensagens; 
mensagens claras e facilitadas para os companheiros; dificultar a mensagem para os adversários; necessidade de estabelecer processos de comunicação entre companheiros e de contra-comunicação em relação a equipe adversária; desenvolvimento de processos de tomada de decisões em relação aos companheiros e adversários.

Mesmo assim, com raras exceções, os livros que servem de instrumentalização para os professores de Educação Física encontrados no contexto brasileiro vêm tratando o ensino dos JEC de forma isolada e desconectada da idéia central do jogo, sem contemplar os elementos de leitura e muito menos as interações (oposição e cooperação) que se estabelecem, dificultando o ensino e a compreensão das ações motrizes no contexto do jogo. Exceto a obra de Greco (1998), reimpressa em 2005, todas apresentam descrições de técnicas e exercícios para ensinar este grupo de modalidade, não instrumentalizando o professor para o ensino de leituras do jogo e aprendizados de situações para o desenvolvimento de processos de tomada de decisão, inviabilizando a apropriação dos saberes sobre o saber corporal, assim como limitando o conhecimento do saber fazer corporal, conforme propõe Bracht(1997). Esta produção bibliográfica não responde a questões como: Que interações estão presentes no passe? Qual o sentido do bloqueio no handebol? Quais as percepções necessárias para realizar uma finalização a gol? Quais as interações que se estabelecem no handebol?

Em relação à instrumentalização do ensino dos esportes, mais precisamente dos esportes coletivos, a Praxiologia Motriz vem sistematizando importantes contribuições no processo de desvelar a lógica interna e essência do jogo, permitindo, assim, intervenções pedagógicas mais precisas, claras e significativas, do ponto de vista de compreensão de jogo. Assim, parte-se do pressuposto de que tal lógica de apreensão do saber poderá tornar-se concretamente mais clara e qualitativamente mais rica quando usamos como instrumento de análise, estudos advindos da Praxiologia Motriz. Alguns exemplos de aplicações desses instrumentos em currículos escolares, práticas introjetivas, ginástica artística, treinamentos e atividades na natureza estão exemplificados no livro "Jogos e esportes: fundamentos e reflexões da Praxiologia Motriz" (RIBAS, 2008).

Mas, o que é Praxiologia Motriz? A Teoria da Ação Motriz, como também é conhecida, surgiu na França com o professor Pierre Parlebas no final de década de 60. O autor, que atuou em escolas e equipes de treinamento, teve como questão central a grande dificuldade de nossa área de estabelecer um objeto próprio de estudo e entendimento do jogo e esporte, assim como o aumento acelerado de manifestações da cultura corporal de movimento, dificultando, assim, a intervenção pedagógica do professor de Educação Física. Uma síntese possível é afirmar que a Praxiologia Motriz consiste no estudo da lógica interna dos jogos e esportes, ou seja, este conhecimento estabelece critérios para estudar todas as formas da cultura corporal de movimento, no sentido de desvelar a essência do funcionamento de cada jogo ou esporte. Assim, na primeira parte do texto, trato de aproximar o leitor com alguns conceitos da Praxiologia Motriz.

Os modelos de estudos dos jogos e esportes que Parlebas elaborou são muitos e requerem, no mínimo, uma obra completa para explorar todas suas facetas para analisar uma modalidade. Por isso, na segunda e principal parte deste artigo, apresentarei o modelo dos Universais, onde estarei evidenciando as características essenciais desta modalidade coletiva que pouco são consideradas na organização das práticas pedagógicas a partir de quatro elementos de análise. São eles: a comunicação práxica; gestemas; praxemas e os papéis ou funções dos jogadores. Encerro o texto mostrando algumas perspectivas de estudo a partir da teoria da ação motriz.

\section{Praxiologia Motriz}

O francês Pierre Parlebas vem construindo os alicerces da Praxiologia Motriz há mais de trinta anos. Tem publicado inúmeros artigos (aproximadamente 50 até 1992, segundo GLEYZE, 1992), realizando habituais colaborações no jornal "Le monde", além de seis importantes obras sobre o tema. A última delas, "Jeux, Sports et Sociétés", publicada em 1999, reúne as principais idéias da área em forma de léxico. Sem dúvida nenhuma, esta é considerada a obra mais importante da Praxiologia Motriz, e é também conhecida como Teoria da Ação Motriz. Nesse livro, a definição de Praxiologia Motriz é a 
seguinte: "Ciência da Ação Motriz e especialmente das condições, modos de funcionamento e resultados de seu desenvolvimento (PARLEBAS, 1999: 264)". Esse conceito não esclarece muito, já que envolve outros termos, desconhecidos de nossa realidade, como é o caso da Ação Motriz.

A Ação Motriz se refere a uma situação social específica do jogo ou esporte. A situação fica mais peculiar já que este objeto está atrelado à lógica interna, que inscreve e determina as Ações Motrizes com base nos regulamentos ou regras da atividade. Complemento essa idéia com as palavras de Serrano Sánchez (1996: 86): “Ainda que sua ordenação de gêneros tenha bases em conceitos psicossociais (cooperação, oposição, inter-relação com o meio físico) e socioculturais (institucionalização, regras, organização oficial, competição), a Ação Motriz só se explica pela sua lógica interna".

A chave do Jogo: a lógica interna, título de capítulo da recente obra de Lagardera Otero e Lavega Burgués (2003), se constitui em outro relevante caminho para esclarecer esta temática. É possível afirmar que a Praxiologia Motriz é o estudo da lógica interna dos jogos e esportes a partir das regras ou normas de funcionamento. A função dos elementos de análise da Praxiologia Motriz é desvelar o mundo dos jogos e esportes a partir da compreensão da essência da lógica interna representadas pelas ações motrizes.

As Ações Motrizes estão inscritas nas normas de funcionamento de cada jogo ou esporte (contrato lúdico), e aí é que Parlebas diferencia a Ação Motriz de qualquer outro movimento. Tirar a areia do rosto durante uma partida de vôlei de praia é muitas vezes crucial para o desempenho do atleta. Caso não realize este movimento, isso poderá atrapalhar as ações seguintes. Mas, segundo a concepção praxiológica, este movimento não é considerado uma Ação Motriz por que não está previsto no regulamento. Agora, saltar e bloquear uma bola, sim, isto é uma das situações motrizes que esta prática nos revela. São as Ações Motrizes que emergem do sistema praxiológico, relativas às suas normas, que interessam à Praxiologia Motriz.

A outra grande característica da Teoria da Ação Motriz se refere à estruturação das atividades, bases encontradas no Estruturalismo, principalmente nas idéias de Levi-Strauss. Em linhas gerais o Estruturalismo consiste em desvelar características elementares que organizam uma determinada sociedade (uma cidade, um país, um bairro etc.), por exemplo, e que se repetem ou a diferenciam de outras. $\mathrm{Na}$ Praxiologia Motriz, essa mesma relação foi feita por Parlebas com o mundo dos jogos. Existem eventos e elementos que poderão se repetir em distintas modalidades. Com essa idéia foi que Parlebas criou, por exemplo, os universais ${ }^{1}$ dos jogos, tema este que será explorado na sequência deste texto.

O exemplo mais utilizado pelos praxiólogos para explicar a concepção de estrutura do jogo está relacionado com a teoria musical. As músicas podem ser apreciadas por um leigo simplesmente por sua beleza sonora, assim como poderão ser desveladas suas sequências, interesse maior dos músicos e estudiosos desse campo. Para os leigos, a sequência de notas também poderá ser interessante, mas não será essencial para apreciá-la. Mas para os músicos e estudiosos, é uma condição sine qua non. São essas estruturas que poderão ser reproduzidas, debatidas, cambiadas, harmonizadas, adaptadas, possibilitando melhor entendimento da sua dinâmica. Assim, para finalizar, Parlebas (1996) nos relata um esclarecedor exemplo:

"Admitamos que cada parte do handebol seja
única; todos os encontros ludo-esportivos ${ }^{2}$
diferem uns dos outros; todos têm sua própria
história e estão salpicados de acontecimentos
originais. Não obstante, estas diferentes
peripécias são resultantes de uma mesma
matriz. Um jogo esportivo não é somente um
puro fantasma entregado às extravagâncias
subjetivas: é, antes de tudo, um corpo de
regras. E esse corpo de regras irá impor sua
regra ao corpo. Define as características
objetivas do jogo, ou seja, sua lógica interna que
irá gerar comportamentos, sem dúvida alguma
diversos, mas todos marcados pelo mesmo
carimbo (p.16)." Os Universais e o Handebol

A obra mais completa de Parlebas, "Jeux, Sports et Sociétés: Lexique de prexéologie motrice" está organizada em forma de léxico da teoria da Ação Motriz, onde, em ordem alfabética, o autor define e explica cada terminologia usada. Dentre vários motivos para a construção dessa obra, o autor explica esta necessidade da

\footnotetext{
${ }^{1}$ Modelos operatórios que apresentam as estruturas de base do funcionamento de todo jogo esportivo e possuidor da lógica interna do mesmo (PARLEBAS, 1996: 16).

${ }^{2}$ Características das atividades motrizes que se referem aos jogos esportivos (PARLEBAS, 1999: 235).
} 
seguinte forma: "Uma linguagem específica traduz um novo modo de considerar as atividades físicas e pode acompanhar uma modificação das práticas esportivas" (PARLEBAS, 1999: 31).

Mas Parlebas não deixa seu leitor desamparado. O autor estrutura esta obra em sete grupos: conceitos básicos, modelos, pedagógica, semiomotriz, sócio-institucional, decisão e de interação. Em cada grupo lista os termos que estão mais associados com a idéia principal. Somente no grupo relativo ao modelo são mais de 30 expressões. Por isso, tive que escolher algumas, a meu ver, as mais importantes para este momento, relativas a modelos da teoria da Ação Motriz.

O principal deles - e a meu ver, o mais indicado para compreender melhor o handebol - é o universal dos jogos esportivos, que o autor define como "modelos operativos que representam as estruturas básicas de funcionamento de todo jogo esportivo ${ }^{3}$ e que são portadores de sua lógica interna (PARLEBAS, 1999: 431). A idéia de modelo se refere a uma construção esquemática e teórica. Vale destacar a observação de Demo (1995) com relação aos modelos estruturalistas da sociedade:

O modelo é sempre simplificador, pois tenta cristalizar em núcleo concatenado e estável a superfície complexa da realidade, apoiando-se na crença de que a subjacência, sendo ordenada (estruturada) e simples, contém a explicação e a "essência" do fenômeno. que poderá ser construído com bases em instrumentos (p.186).

O primeiro ponto a comentar é que os modelos que Parlebas constrói se referem aos jogos e não a uma sociedade. O autor identifica uma série de elementos universais para poder explicar os esportes, que estão orientados pelas regras. Quero dizer com isso que esta sistematização é possível se considerarmos somente este caminho, de entender as ações motrizes que emergem das distintas manifestações de jogos e esportes, e não especificamente de um determinado evento esportivo ou aula de Educação Física.

Assim, a Praxiologia Motriz evidencia essa gramática dos jogos esportivos, como vem sendo

\footnotetext{
3 PARLEBAS (1999) entende como Jogo Esportivo toda situação motriz de confronto codificada, denominada jogo ou esporte pela instância social (p.196). Entretanto, neste estudo tenho adotado a terminologia jogo, já que em nossa realidade
}

denominado por Lagardera Otero e Lavega Burgués (2003), partindo de um criterioso estudo dos jogos e esportes com base em conhecimentos da sociologia, antropologia e linguística, onde Parlebas elabora conceitos básicos, modelos, classificações e caracterização de interações que evidenciam a essência dessas manifestações. Os Universais se constituem em um importante modelo de análise de Jogos e Esportes que identificam as estruturas objetivas que explicam a lógica interna (Parlebas, 1999). Os universais estão constituídos dos seguintes parâmetros de análise: a comunicação práxica; os gestemas; os praxemas; papéis ; sub-papéis; o sistema de pontuação; e a rede de interação de marca. Na seqüência, iremos realizar o exercício de explicar o jogo de handebol partindo de quatro elementos dos universais, no caso, a comunicação práxica, os gestemas, os praxemas e os papéis.

\section{A comunicação práxica}

Comunicação práxica se refere à interação motriz essencial, ou seja, interações motrizes instrumentais entre os participantes, caracterizando como fenômeno maior na tarefa motriz. Quero dizer com isso que, mais importante que lançar a bola com técnica refinada à meta adversária, é criar estratégias para chegar ao gol do adversário e defender-se. As finalizações só acontecerão se situações claras de gol forem criadas. Para construir essas estratégias é essencial considerar a comunicação práxica. Parlebas divide a comunicação em duas formas: direta (rede de comunicação e rede de interação) e indireta (gestema e praxema). Estes são os quatro modelos que iremos apresentar na sequência.

A rede de comunicação motriz revela as distintas formas possíveis de comunicar-se em qualquer jogo desportivo ${ }^{5}$. A expressão rede de comunicação motriz parece não ser a mais adequada já que além da comunicação (cooperação) este modelo nos mostra a contracomunicação (interação de oposição) do jogo.

o jogo esportivo nos remeteria ao esporte e não a essa concepção mais ampliada que sugere Parlebas.

${ }^{4}$ A tradução original trata de rol e sub-rol. Porém, neste texto iremos utilizar o termo papel e sub-papel expressões que se tornam mais claras em português.

${ }_{5}^{5}$ Utilizaremos esta expressão proposta por Parlebas (1999) para indicar "toda situação motriz de confronto codificado, denominado jogo ou esporte pela instância social (p.196)". 


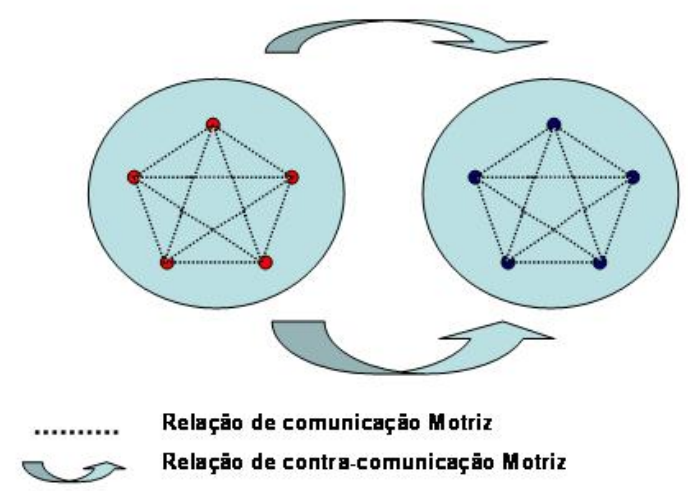

Figura 1. Rede de comunicação motriz do basquetebol (Parlebas, 1999: 388)

Na figura 1 temos a rede de comunicação do basquetebol, onde os pontinhos representam os jogadores, as linhas tracejadas, as relações de oposição ou contracomunicação, e as linhas contínuas, as relações de comunicação ou cooperação. Esta estrutura nos mostra, em forma de gráfico, que são dois grupos que se opõem, e totalmente solidários entre companheiros de equipe. Não existe mais nenhuma outra possibilidade dentro desta estrutura no que tange à rede de comunicação.

O handebol apresenta as mesmas características do basquetebol, ou seja, consiste no confronto (oposição) entre duas equipes que cooperam entre si. A interação de cooperação é denominada de comunicação, que quer dizer que, quanto melhor essa relação, maior será a possibilidade de obter êxitos nas ações de ataque e defesa. Os jogadores devem conhecer muito bem uns aos outros para que no decorrer do jogo o processo de tomada de decisão seja mais eficaz. Vamos exemplificar.

Se, durante um jogo, na situação de defesa, se conhecem de antemão as limitações defensivas do companheiro de equipe, em todas as situações em que as chances de meu companheiro falhar sejam maiores pode-se antecipar a cobertura. Assim, já me preparo para dar o auxílio e tentar interferir na sequência da jogada. O mesmo poderá acontecer no ataque, onde poderei passar sem olhar, sabendo seu posicionamento, ou então, realizar uma troca de posição sem provocar um desequilíbrio do ataque.

Quero chamar a atenção de um aspecto extremamente importante que venho observando nos treinamentos. Até o momento, entendo que essas relações de cooperação são as mais enfatizadas em nossos programas de treinamento. Os exemplos mais claros são as jogadas ensaiadas. O problema começa quando as jogadas ensaiadas são realizadas independentemente do posicionamento da defesa, desconsiderando as interações de oposição.

Os treinamentos realizados durante minha experiência esportiva no Corinthians e depois na Adufsm, em Santa Maria, RS, enfatizavam uma sequência muito interessante de jogada para ser empregada em determinadas situações de jogo ou sistemas defensivos. Mas, muitas vezes, no decorrer da jogada apareciam opções melhores de jogo, e os jogadores, extremamente condicionados à sequência da jogada, não conseguíamos tomar as melhores decisões já que treinavam com ênfase a sequência e não as variações ou desdobramentos que poderiam surgir.

Entretanto, os treinadores da Associação Desportiva Universidade Federal de Santa Maria (ADUFSM) o prof. Luis Carlos Décimo da Fonseca, e prof. Luiz Osório Cruz Portela, entre 1987 e 1989, foram os primeiros treinadores, de quem tive contato, que começaram a chamar a atenção do grupo para as possibilidades de 
variação das jogadas. O único problema que percebi foi o fato de que não tínhamos um processo pedagógico sistematizado para perceber 0 adversário e trabalhar essas variações. As orientações eram mais teóricas, ou seja, explicavam tudo aquilo que poderíamos fazer em cada situação, mas não praticávamos a partir de exercícios. Por exemplo, trabalhar com facilitações da defesa, ou com a defesa antecipando situações para que $o$ ataque fizesse a variação, enfim, exercícios e jogos que pudessem despertar nossa percepção dentro da quadra. Mesmo assim, com uma equipe nova, inexperiente e de baixa estatura, conseguíamos ir para as finais ou semifinais dos campeonatos brasileiros nesse período (entre 1987 e 1989), por termos uma equipe bastante coesa dentro da quadra, ou seja, de acordo com critérios praxiológicos, com um processo de comunicação bastante desenvolvido. Mais adiante, nas considerações finais, irei mostrar alguns parâmetros que deverão ser considerados nas situações de ensino e treinamento do handebol.

A situação de oposição, outro elemento da comunicação práxica encontrado no handebol, não deve ser pensada desvinculada da cooperação. Conforme apresentei, no instante em que tratei da cooperação, parágrafos atrás, indiretamente me referia à oposição (posicionamento do adversário, variações em função da defesa, entre outros). Farei o mesmo agora onde estarei tratando da oposição, e enfatizarei estes elementos, mas uma vez ou outra, mencionarei aspectos relativos à cooperação.

Quando ilustramos a oposição em um gráfico, a ideia que passa é que todos os adversários irão se opor da mesma forma durante todo o jogo. Nada melhor que exemplos para desmistificar este gráfico. No handebol, cujo objetivo maior é fazer o gol e evitar que o adversário faça o mesmo, na situação de ataque sempre haverá duas linhas de oposição. Uma é a do goleiro e a outra da defesa, ou seja, o atacante, ao superar a defesa, também dever superar o goleiro. Esta é a situação que se dá enquanto estamos atacando. O objetivo é superar aqueles adversários que estão mais próximos, na nossa zona de atuação, a fim de facilitar nossa ação seguinte que é de superar o goleiro. A oposição acontece não só em relação ao marcador direto, mas com todos os marcadores que em alguns momentos, diminuem os espaços de atuação, ou diminuem as opções de passe. Assim, a marcação direta não seria a única forma de oposição, teríamos a cobertura, diminuição de espaços do ataque, antecipação de passes ou marcação individual sem deixar receber, entre outras formas.

Outra característica que deve ser destacada da oposição em jogos de cooperação e oposição é que esta se dá entre todos ao mesmo tempo. Vamos às explicações. Quando tratei das formas no parágrafo anterior já foi possível ilustrar um pouco dessa idéia quando apresentado no handebol a possibilidade de opor-se de diferentes maneiras. Sendo assim, no momento em que busca-se encontrar um melhor posicionamento na situação de ataque, com ou sem bola, deve-se avaliar todos os setores da defesa adversária, assim como o posicionamento e trajetórias dos companheiros para decidir pelo melhor espaço. Este pensamento deve ser atrelado a uma organização coletiva de jogo. O resultado dessa oposição é que os seis atacantes deverão trabalhar de forma que o coletivo consiga encontrar a melhor alternativa de ataque. Entendo como um complexo sistema de interações, onde não basta superar nosso opositor direto, se não criarmos a melhor chance coletiva. Em outras palavras, não adianta um jogador realizar uma finta e finalizar, se esta não for a melhor alternativa coletiva.

A mesma lógica da situação de ataque vale na função de defensor. Só gostaria de explicitar que no handebol são sete defensores contra seis atacantes, sendo que seis estão posicionados na linha dos seis metros e o outro defensor estará no gol. Aponto isso, apenas para destacar que é possível identificar as diferentes combinações e decisões que a defesa poderá tomar em função desse coletivo de sete jogadores, como são os casos dos bloqueios, facilitação do ataque nas situações em que o goleiro tem maior facilidade (pontas, por exemplo) e em função do aproveitamento do adversário.

Mas, por que não estamos levando em consideração esses princípios em nossos programas de treinamento como demonstrou o professor Michel Saad (2002) Neste estudo, o autor tratou de analisar os procedimentos utilizados por treinadores de futsal de base da cidade de Florianópolis e constatou que a tarefa de maior preferência dos treinadores se restringia 
a treinamentos técnicos do jogos, ou seja, uma metodologia diretiva. Por que as metodologias não vêm contemplando elementos relativos à interpretação de mensagens do jogo, conforme foi constatado neste estudo? Por isso, entendo que, a partir dessas primeiras reflexões das comunicações práxicas, temos muito que avançar em nossos processos metodológicos de ensinoaprendizagem dos jogos esportivos coletivos.

\section{Os gestemas e praxemas}

Os códigos gestêmicos ou gestemas são formas de comunicação gestual que facilitam as ações de relação entre os jogadores. Por exemplo, levantar o braço para pedir a bola, ou sinalizar informando a trajetória de um deslocamento. Estes gestos auxiliam na relação de comunicação entre companheiros. Essas informações poderão ser decodificadas por jogadores de ambas as equipes, gestemas unívocos, ou então decodificadas somente por jogadores da mesma equipe, gestemas particulares (PARLEBAS, 1999). Esses elementos são bastante claros no handebol e, na iniciação, praticamente essenciais para o bom desempenho do grupo. No entanto, quanto maior o nível do grupo, mais sutis e raros serão os gestos já que eles antecipam o que iremos fazer (gestemas unívocos), facilitando, assim, o processo de leitura do nosso adversário.

Outro elemento da comunicação práxica, no caso, indireta, são os praxemas, que estabelecem um tipo de comunicação que facilita a coordenação com um companheiro ou a rivalidade com um contrário mediante a própria execução de determinadas ações, como por exemplo, deslocar-se em direção ao gol, saltar, armar o braço para lançar a gol, correr em uma direção para receber a bola (PARLEBAS, 1999).

Em linhas gerais, os praxemas são os gestos e formas de atuação característicos de cada jogador, tanto companheiro como adversário, que orientam a nossa ação. Por exemplo, um jogador que tem a posse de bola nos nove metros e se desloca na diagonal, em direção ao centro nos dá uma série de informações praxêmicas em relação ao adversário. Isto, combinado com as outras ações praxêmicas dos adversários e também com as ações praxêmicas de minha equipe, é que irá orientar a ação individual de cada jogador. Aqui temos o que podemos chamar de leitura momentânea do jogo para o processo de tomada de decisão. Quanto melhor a leitura praxêmica, melhores serão as alternativas de antecipação.

No handebol de alto nível, o bom processo de leitura de praxemas por parte do coletivo será cada vez mais importante para a equipe. Neste caso, não adianta ter um bom jogador que consiga perceber as ações e possibilidades de ataque e tomar boas decisões. Estas deverão ser interpretadas de forma similar por toda equipe. Por exemplo, em uma situação de defesa, posso perceber que o ponta sempre entra de segundo pivô quando o armador do lado contrário sobe para lançar. Entretanto, se eu estiver marcando no lado oposto, quem deverá perceber estas ações são os três jogadores do outro lado da zona de defesa. Um gesto meu neste momento (gestema) não poderá ser eficiente para alertar meus companheiros já que as jogadas acontecem muito rápido. O mais indicado é evidenciar a leitura praxêmica para meus companheiros, função principal do treinador, que deverá ensinar o posicionamento (dinâmico) da defesa a partir do processo de leitura do ataque.

\section{Papéis e funções dos personagens dos jogos}

Este aspecto é estudado mediante um tipo de universal denominado Sistema de Função. A partir deste critério é possível desvelar as possíveis formas de adotar róis ou papéis e as possíveis mudanças que se podem produzir entre eles. Não é a mesma coisa jogar na função de goleiro e jogar na linha, no handebol, ou então, escapar, no pega-corrente, ou fazer parte da corrente, sendo pegador. Inclusive, estes papéis poderão variar na mesma partida, como é o caso do pega ajuda, onde a maioria começa fugindo do pegador e, no final do jogo, todos deverão ajudar a pegar, até terminar o jogo. Parlebas (1999) esclarece que as funções são: "Classes de comportamentos motores associadas a um regulamento preciso, em um jogo esportivo. Todo papel sociomotor está associado a um estatuto que codifica a prática (p. 312)".

Para identificarmos a função, será necessário entender que relações poderão estabelecer-se em um jogo. Parlebas em sua obra mais recente, o léxico, identifica três grandes setores de ações e três status sociomotores para explicar estas relações. Entretanto, para o presente texto, utilizaremos diretamente as reflexões de Hernández Moreno (2000), que trata dos 
conteúdos esportivos na Educação Física Escolar desde a Praxiologia. Neste texto o autor caracteriza os papéis e sub-papéis de cada atividade. Quanto aos papéis, o exemplo vem dos jogos que apresentam como característica principal a cooperação e oposição, os chamados jogos coletivos (handebol, futebol, basquetebol, voleibol etc.). Nessas modalidades, o autor mostra que os papéis estratégicos que o jogador pode assumir são: Jogador com a bola, Jogador sem a bola da equipe que tem a posse de bola e Jogador da equipe sem a bola.Vamos esclarecer melhor estas relações já que destacam outra característica dos jogos coletivos, no nosso caso, do handebol.

- Jogador com a bola: Nesta situação no handebol, temos as seguintes ações: colocar em jogo a bola, avançar com a bola, proteger a bola, passar a bola, lançar a gol, quicar e retê-la para passar o tempo, fintar, quicar e ocupar espaços (desmarcar-se), quicar e reduzir espaços (pressionar), colocar-se em posição de ataque, perder a bola, fazer falta ou violar a regra e receber falta.

- Jogador sem a bola da equipe com a bola: avançar em direção ao ataque, ocupar uma posição no sistema, desmarcar-se, bloquear, fintar, ampliar espaços, reduzir espaços, ajudar a um companheiro, pedir a bola, receber a bola, dirigir o jogo, esperar, fazer falta ou violar a regra e receber falta.

- Jogador da equipe sem a bola: retornar à defesa, ocupar uma posição no sistema, fintar, passar o tempo, reduzir espaços, ampliar espaços, antecipar-se, ajudar um companheiro, entrar ou carregar um adversário, interceptar ou desviar a bola, recuperar a bola, esperar, fazer falta $\mathrm{e}$ receber falta.

O primeiro ponto que gostaria de esclarecer é a ideia de que o jogo acontece a todo momento. Parece uma conclusão um tanto óbvia, mas não vemos isso com muita frequência como conteúdo de ensino de JEC. Basta prestar atenção à forma como são organizados os dados estatísticos de jogos coletivos para detectar esta incoerência. No futebol, onde temos mais acesso a estas estatísticas, as contradições se repetem. O jornal Folha de São Paulo (ESPORTE, 2003) do dia 04 de agosto de 2003 apresenta alguns dados estatísticos relativos às equipes que participam do maior campeonato Brasileiro da história, fazendo um resumo do primeiro turno. Divide as informações em destaques individuais, destaques coletivos e como foram os gols. Para os destaques coletivos, as informações são relativas às equipes (média de gols marcados e sofridos, dribles, cruzamentos, desarmes, finalizações e lançamentos). Os destaques individuais se referem aos jogadores, ou seja, artilheiros, defesas, desarmes, passes certos, finalizações e faltas recebidas. Na descrição de como foram os gols, foram observados onde a bola entrou, região do campo (dentro da pequena área, dentro da grande área e fora da área), e forma de finalização (cabeça e pé).

Todos os dados apresentados pela Folha dão ideia de algumas características e dos destaques das equipes. É um importante olhar do panorama geral do primeiro turno do campeonato. Mas, é possível entender apenas uma pequena parte deste conjunto. Quando os dados dos destaques coletivos mostram que a equipe do Flamengo tem o maior número de passes certos, a do Guarani, o maior número de desarmes ou a do Internacional o maior número de cruzamentos, é possível entender, em parte como esses coletivos se organizam. Mas de forma alguma expressa a sequência de um coletivo. Por exemplo, como a equipe do Grêmio ataca normalmente? Que movimentações acontecem? E o Cruzeiro, melhor ataque do campeonato, como articula suas jogadas? Que situações em relação aos espaços de jogos são articuladas? Não quero dizer com isso que essas informações apresentadas no caderno de esportes da Folha de São Paulo não sejam importantes para entender melhor as equipes no campeonato, mas que se tornaria mais completa e precisa se, partindo da essência da atividade, agregássemos informações relativas à ocupação dos espaços, idéia de um projeto de pesquisa que estou começando a desenvolver. Em linhas gerais, gostaria de saber em que condições acontecem os passes, os cruzamentos, os golos, os desarmes, enfim, não somente a ação mas a posição no campo ou quadra e o posicionamento dos outros jogadores.

Outro aspecto que encontro relevante, partindo das funções dos jogos esportivos coletivos, se refere ao processo de tomada de decisão que foi apresentado nos livros de Iniciação Esportiva Universal (IEU), coordenado pelo professor Pablo Juan Greco (1998) da Escola de Educação Física, Fisioterapia e Terapia Ocupacional da UFMG, do qual participei em algumas partes. Este estudo foi publicado em 
1998 e muitos pontos foram pensados e redimensionados de lá para cá. Mas apresentarei apenas algumas idéias da Praxiologia Motriz em relação ao processo de tomada de decisão no handebol que poderão ser debatidas com maior profundidade em outros momentos.

No segundo volume da obra Iniciação Esportiva Universal: Metodologia da Iniciação Esportiva, dedicamos boa parte para apresentar a metodologia para o desenvolvimento técnicotático realizado de forma integrada, que visa não descontextualizar a situação real de jogo, onde destacamos o processo de tomada de decisão. Em linhas gerais, seria reconstruir diversos momentos do jogo onde levamos nosso aprendiz a desenvolver o processo de tomada de decisão em algumas situações de jogo. É importante frisar que, neste trabalho, a tomada de decisão se referia somente ao jogador que tinha a posse de bola, ou seja, passava a idéia de que os companheiros não precisavam tomar decisões em função dos espaços de jogo. Sintetizando minha reflexão, quero dizer que devemos considerar nos procedimentos de treinamento 0 processo de tomada de decisão de todos os jogadores envolvidos na atividade e não somente do jogador que detém a posse de bola.

Um bom jogador de handebol, a partir de um determinado nível de competição, não consegue mais decidir uma partida sozinho. Ele dependerá do grupo para que este explore as mais diversas situações, ou seja, não basta este jogador saber tomar decisões se o restante do grupo não acompanhá-lo neste processo. Por isso, todos deverão aprender a tomar decisões, a todo instante, com ou sem a posse de bola.

Outro ponto que não deve ser desarticulado do tema que acabamos de comentar se refere ao processo de leitura do jogo. Todos deverão aprender a desenvolver um processo de leitura similar para que a sequência do jogo aconteça de forma mais fluente. Na prática, seria o caso de, em uma situação de ataque, no instante de uma movimentação, todos saberem o que fazer na sequência da movimentação, assim como suas possibilidades de variações, ou seja, se a defesa não acompanhar um engajamento, é bem provável que, na sequência da jogada, sobre para o ponta ou armador do mesmo sentido em que está acontecendo a jogada.

\section{Comentários Finais}

Ao final deste texto, se faz necessário um esclarecimento sobre o caminho de ilustração que foi escolhido para apresentar os elementos da Praxiologia Motriz. O leitor deve ter percebido que me utilizei de minhas vivências no âmbito do handebol para explicar os conceitos destacados dos universais. Isso não quer dizer, de maneira alguma, que o conhecimento praxiológico está voltado para o esporte de alto nível, mas sim, que este conhecimento se constitui numa relevante ferramenta para que professores e alunos compreendam o mundo dos esportes, inclusive, trazendo novos rumos para a construção de uma didática de ensino dos esportes. Vale ressaltar que esta discussão só terá sentido se forem situadas e vinculadas a uma prática pedagógica crítica da Educação Física (Crítico superadora ou crítico emancipatória), enfoques com que venho dialogando. Por isso, o título do artigo remete o conhecimento praxiológico à instrumentalização da prática pedagógica por que entendemos que este rico e vasto conhecimento sobre o jogo e esporte poderá facilitar ainda mais as decisões pedagógicas dos professores assim como, orientar o aluno no saber fazer e sobre o fazer corporal.

$\mathrm{Na}$ abordagem crítico-superadora que temos sistematizado através dos cinco momentos articulados propostos por Saviani(1997), em estudos preliminares, situamos que estes conceitos da Praxiologia Motriz poderão orientar a instrumentalização dos professores e alunos, espaço dedicado à apropriação de instrumentos (conteúdos), socialmente produzidos e culturalmente preservados. A Praxiologia Motriz, por sua vez, organiza com maior propriedade e critérios as distintas manifestações da cultura corporal de movimento, trazendo à tona a essência dos jogos e esportes, encaminhando orientações metodológicas para o saber fazer e sobre o fazer corporal, e principalmente, sobre a lógica interna de funcionamento que poderá ser articulada com o contexto sócio-cultural.

$\mathrm{Na}$ abordagem crítico-emancipatória, objeto de outro estudo, temos aproximado este conhecimento principalmente na ressignificação da prática pedagógica do esporte institucionalizado, onde professores e alunos terão em mãos critérios mais consistentes para conhecer e ampliar os sentidos/significado dos 
aspectos que compõem 0 esporte. As competências objetiva, social e comunicativa também se constituem em espaços de contatos do conhecimento praxiológico com este enfoque já que o aprofundamento no conhecimento da lógica de jogos e esportes poderá subsidiar a competência objetiva e sustentar o entendimento das competências social e comunicativa.

É evidente que estes dois parágrafos acima apenas ilustram os caminhos que o conhecimento praxiológico poderá dar a distintos enfoques da Educação Física. Orientações sobre estas relações também foram encaminhadas por Ribas (2005), que apontou, de forma geral, contribuições da Praxiologia Motriz para a prática pedagógica. Os exemplos apresentados neste artigo indicam que a Praxiologia Motriz não se constitui em um enfoque pedagógico da Educação Física mas sim, um conhecimento científico, com critérios consistentes, que trazem à tona as distintas formas de funcionamento de jogos e esportes. Assim, neste momento, estamos buscando situá-la nos enfoques críticos da Educação Física, justamente para orientar a utilização de seus instrumentos, sem perder de vista a prática social, identificando como e em que momento este conhecimento irá ajudar a prática pedagógica do professor.

No que tange à Praxiologia Motriz, nesses últimos anos tem sido cada vez mais evidente a relevância desse conhecimento na construção de uma didática para o ensino do jogo e do esporte. Nas modalidades coletivas, como é o caso do handebol, é possível perceber que a Teoria da Ação Motriz poderá dar um novo rumo ao processo de ensino aprendizado, apontando para novos caminhos para trilharmos. De espaços de aprendizagens, com ênfase nas técnicas, desarticulados do jogo, para uma técnica construída em função da lógica do jogo, das necessidades e possibilidades de cada participante; de treinamento tático combinado e sequências pré-definidas, para construção de jogadas a partir de processos de leituras do jogo e de tomadas de decisão.

Neste texto foi possível apresentar alguns exemplos em função de pontos discutidos calcados nos universais dos jogos de Parlebas. Entretanto, a meu ver, faltam reflexões mais aprofundadas do conhecimento praxiológico para os jogos esportivos coletivos. Atualmente existem autores da Praxiologia que vêm desenvolvendo estudos nessa linha, como é o caso do professor José Hernández Moreno da Universidade de Las Palmas de Gran Canária, Espanha, que em 1994 publicou o livro Análisis de las Estrutucturas del Juego Deportivo (Hernández Moreno, 1994), assim como uma série de artigos sobre o tema.

Em português, a reflexão que converge com os princípios da Praxiologia Motriz no âmbito dos jogos coletivos é a proposta do IEU, que já foi mencionada neste estudo, até por que encontramos nas bases dessa metodologia um importante autor que foi diretamente influenciado pela Praxiologia Motriz de Parlebas, no caso, o também francês Claude Bayer. Por isso, se tivermos a oportunidade de darmos sequência à discussão da proposta do IEU, certamente a Praxiologia poderia dar novas e importantes contribuições, conforme destaquei em alguns pontos deste texto a partir dos Universais dos jogos.

\section{Referências}

BRACHT, V. Educação Física: conhecimento e especificidade. In: SOUSA et al. Trilhas e partilhas: educação física na cultura escolar e nas práticas sociais. Belo Horizonte: Ed. UFMG, 1997, p.13-23.

DEMO, Pedro Metodologia científica em ciências sociais. $3^{\mathrm{a}} \mathrm{ed}$. Rev. E Ampl. São Paulo: Atlas, 1995.

ESPORTE: Confira os números do Brasileiro 2003. Folha de São Paulo, São Paulo, página D7, 5 de maio, 2003.

GLEYZE, Jacques. L'EPS au XXs en France. Revue EPS. № 15, 1992.

GRECO, P.J. (organizador) Iniciação Esportiva Universal: Metodologia da Iniciação Esportiva. Belo Horizonte: Ed. UFMG, 1998.

HERNÁNDEZ MORENO, José. Fundamentos del Deporte: Análisis de las estructuras del juego deportivo. INDE Publicações: Barcelona. Primeira edição, 1994.

LAGARDERA OTERO, Francisco e LAVEGA BURGUÉS, Pere. Introdución a la Praxiología Motriz. Barcelona, Editorial Paidotribo, 2003.

PARLEBAS, P. Los universales de los juegos desportivos. Revista de Praxiologia Motriz, Las Palmas de Gran Canária. n. 0, v.1, p. 15-30, 1996. 
PARLEBAS, P. Jeux, Sports et sociétés: lexique de praxéolgie motrice. Institut du sport et de l'éducation physique, 1999.

RIBAS, João Francisco Magno. Praxiologia Motriz: construção de um novo olhar dos jogos e esportes na escola. Motriz (Rio Claro), Rio Claro, SP, v. 11, n. 2, p. 103-110, 2005.

RIBAS, João Francisco Magno (org.). Jogos e esportes: fundamentos e reflexões da Praxiologia Motriz. Santa Maria: Editora da UFSM, 2008.

SAAD, Michél Angillo. Estrutura das sessões de treinamento técnico-tático nos escalões de formação do futsal. Dissertação de Mestrado em Educação Física apresentada a Corrdenação de pós-Graduação em Educação Física da Universidade Federal de Santa Catarina, Florianópolis, 2002.

SAVIANI, D. (1997) Escola e democracia: polêmicas do nosso tempo. Campinas, SP: Autores Associados.

SERRANO SÁNCHES, J.A. Acerca de una confrontación de los problemas de estatuto científico entre la educación fisica y la Praxiologia Motriz. Revista de Praxiologia Motriz, Las Palmas de Gran Canárian. n. 0, v.1, p. 65-110, 1996.

Endereço:

João Francisco Magno Ribas

Universidade Federal de Santa Maria

Centro de Educação Física e Desportos

Departamento de Desportos Coletivos

Faixa de Camobi, Km 9 Campus Universitário

Santa Maria RS Brasil

97105-900

e-mail: ribasjfm@hotmail.com

Recebido em: 01 de janeiro de 2009.

Aceito em: 10 de novembro de 2009.

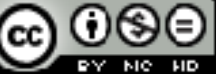

Motriz. Revista de Educação Física. UNESP, Rio Claro, SP, Brasil - eISSN: 1980-6574 - está licenciada sob Licenca Creative Commons 